\title{
Robotic System for Physical Training of Older Adults
}

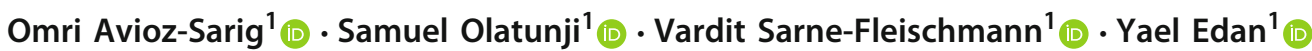

Accepted: 4 September 2020 / Published online: 30 September 2020

(c) The Author(s) 2020

\begin{abstract}
Physical exercise has many physical, psychological and social health benefits leading to improved life quality. This paper presents a robotic system developed as a personal coach for older adults aiming to motivate older adults to participate in physical activities. The robot instructs the participants, demonstrates the exercises and provides real-time corrective and positive feedback according to the participant's performance as monitored by an RGB-D camera. Two robotic systems based on two different humanoid robots (Nao, toy-like and Poppy, mechanical-like) were developed and implemented using the Python programming language. Experimental studies with 32 older adults were conducted, to determine the preferable mode and timing of the feedback provided to the user to accommodate user preferences, motivate the users and improve their interaction with the system. Additionally, user preferences with regards to the two different humanoid robots used were explored. The results revealed that the system motivated the older adults to engage more in physical exercises. The type and timing of feedback influenced this engagement. Most of these older adults also perceived the system as very useful, easy to use, had a positive attitude towards the system and noted their intention to use it. Most users preferred the more mechanical looking robot (Poppy) over the toy-like robot (Nao).
\end{abstract}

Keywords Older adults $\cdot$ Physical activity $\cdot$ Feedback $\cdot$ Humanoid robot $\cdot$ Kinect $\cdot$ NAO $\cdot$ Poppy

\section{Introduction}

The aging population rate is rising rapidly [1]. With age there is a decline of physical and mental capability $[2,3]$. Inactivity of older adults often results in functional decline, loss of independence and increased disease burden [4]. Physical activity via exercises can delay, prevent, or even reverse these effects [4]. However, older adults do not engage in exercises as much as is recommended for their health [4].

Several technologies have been developed to encourage physical activities such as exergames for mobility [5] (e.g. Wii Fit [6], [7]), virtual reality simulators [8], smartphone applications [9], embodied conversational agents, videobased games and dance [5]. Robot coaches have been used to encourage children exercising [10] and have been proved

Omri Avioz-Sarig

sarigomr@post.bgu.ac.il

Yael Edan

yael@bgu.ac.il

https://smartrobabcbgu.wixsite.com/iemirl

1 Department of Industrial Engineering and Management, Ben-Gurion University of the Negev, Beer-Sheva 8410501, Israel to be effective in terms of companionship and social interaction [10]. Previous research revealed that robot coaches are as effective as a human coach [11] and preferable to a virtual coach [12-14].

Development of robotic applications in the eldercare domain [15] have been aimed at providing physical support ${ }^{1,2}$ [16], social interaction ${ }^{3}$ [17-20], cognitive stimulation $[18,21]$ and safety monitoring ${ }^{4}[22]$. The current work focused on development of a robotic system for physical training of older adults. Interaction parameters related to the feedback provided by the robot as well as the influence of the appearance of the robot were evaluated.

Feedback, as an important element of the interaction with the robot, must be provided appropriately to be effective [2325]. Positive feedback during exercise sessions significantly benefits the experience of older adults $[12,26]$. Negative feedback is known to reduce the user's motivation $[27,28]$.

Feedback can be provided to the users via different modalities, including: tactile, haptic, auditory, visual or any

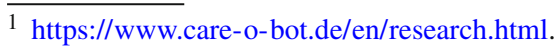

2 https://www.robotcaresystems.com/.

${ }^{3}$ https://www.intuitionrobotics.com/elliq/.

${ }^{4}$ https://kompairobotics.com/why-robots-can-help-frail-people/.
} 
combination of those [29-32]. Speech is considered a natural means of providing feedback, and can provide encouragement and support to increase the users motivation [32]. However, it may also distract the user, and might be missed in the case of elderly people who may suffer from a decreased hearing [33]. Visual feedback suitable for remote humanrobot collaboration [29] could include LEDs to provide better understanding of the robot's state and actions [34]. Facial expression is an important mean of visual feedback in HRI [35], since it can provide useful information [35]. It also has the potential to make the robots behavior more understandable [36] and attractive [25] since the robot seems more intelligent. Combination of visual feedback and speech can be efficient [32,35] and lead to improved collaboration between the human and the robot [34].

The timing [37] of feedback influences the interaction with the system and its effectiveness [32,34]. Feedback can be immediate or delayed, frequent or infrequent [23]. Suitable timing of feedback advances natural flow of communication which helps the user accept the robotic agent communication partner [37]. Adequately timed feedback maintains comprehension in the communication, whereas feedback given too late causes confusion. The temporal proximity between users' input and the robots' response also has been noted to affect the naturalness of the interaction [38]. Timing of feedback could also be continuous or discrete. Continuous feedback proved to improve the trust of the user in the robot $[39,40]$ and decrease the users' workload [39]. However, continuous feedback could lead to presentation of too much information [41]. This can result in information overload and decrease the performance of the user [41].

The current study aimed to find the suitable mode and timing of the feedback provided by a physical training robot for older adults, in order to improve the interaction between the users and the robot as well as to increase the users' motivation to consistently engage in their exercise sessions.

Previous research also revealed that robots with anthropomorphic appearance tend to engage users to interact with the robots in a way that is similar to human-human interaction [42]. This tuned the ongoing development of robotic coaches towards the direction of humanoid robots or robots with some semblance of human-likeness [12]. Such developments involving humanoid robot coaches [12,13] engaged the users in upper limb training sessions. The robots (Bandit and R1) were larger in dimension, closer to human-size and mounted on a wheeled base. This presents a different anthropomorphic impression on the user compared to the smaller sized humanoid robots used in our study which we presume can be more easily handled by the user for personal use. The robots used in our study also had higher degrees of freedom compared to Bandit, providing a wider range of exercises.

We therefore also conducted an exploration of user preferences while training with two forms of humanoid robots to determine which of the robots yields better satisfaction.

The article is organized as follows: Sect. 2 presents details of the overall system design while Sect. 3 describes the method used for experimental evaluations of the design. Section 4 is devoted to the results of the experiments conducted followed by Sect. 5 that discusses the obtained results. Conclusions and suggestions for future work are summarized in Sect. 6.

\section{System Design}

\subsection{Overview}

The system design was focused on motivating older adults to regularly observe and complete their exercise sessions. It was hypothesized that system effectiveness depends on the robot type and on the timing and mode of feedback which would encourage the users to cooperate and complete the training. The older adults may not be aware if their actions accurately corresponded to what the robot required them to do. The robot therefore notified them if they were not doing the exercises correctly. This ensured that the older adults were aware of the correctness of their actions at every point of time [39]. The most suitable timing and mode of feedback for improved interaction were therefore explored.

The overall description of the system components is described in the following subsections:

\subsection{Hardware Description}

The system hardware included a humanoid robot (Fig. 1), which demonstrates the exercises for the users, connected to a RGB-D camera to monitor the users performance and exercise sessions.

Two types of humanoid robots were used as robotic coaches for comparison purposes (Fig. 1): Nao robot (a toylike robot) and Poppy robot (a more mechanical-looking robot).

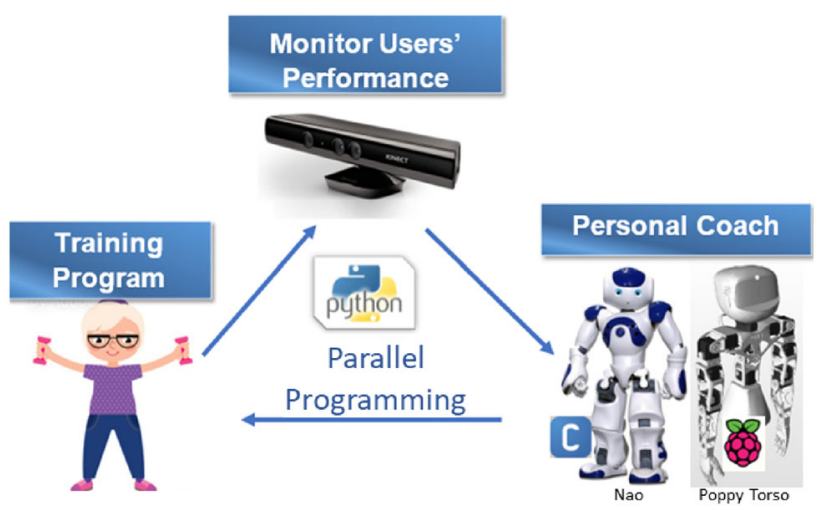

Fig. 1 The Developed System 
The Kinect was used as the RGB-D camera for tracking performance because it was accessible, applicable and had a software development kit equipped with skeleton tracking. The depth camera provides a more accurate view of the users movements compared to a conventional RGB camera. This aids the feedback process by giving the users information regarding their performance. The robotic coach was programmed to instruct the users for the different forms of exercises.

The developed algorithm included parallel programming of each robot with the Kinect.

\subsubsection{Nao Robot}

Nao is an autonomous, programmable humanoid robot developed by Aldebaran-Robotics, a French robotics company ${ }^{5}$. Its height is $57 \mathrm{~cm}$ and its weight is $4.3 \mathrm{~kg}$ [43]. Nao's main technical features include 25 degrees of freedom (DOF), sensors in its head, hands and feet, sonars, 4 directional microphones and loudspeakers, and two cameras. The operating system is NAOqi which is an embedded GNU/Linux distribution.

\subsubsection{Poppy Robot}

Poppy is an open-source 3D printed humanoid robot. Its full body height and weight are $53 \mathrm{~cm}$ and $3.5 \mathrm{~kg}$, respectively [44]. Only the torso of the robot was available at the time of the study and it was therefore used in the experiments without the legs. Poppy was designed to be anthropomorphic with 25 DOFs including a 5 DOFs articulated trunk [45] and LCD screen for display, on which a facial impression was added.

\subsubsection{Kinect}

The Microsoft Kinect sensor for windows is a low-cost sensor that integrates a depth sensor, color camera, and a microphone $[46,47]$. The sensor can provide full-body 3D motion capture, skeleton data, voice recognition and facial recognition [47].

\subsection{System Development}

System development included characterization and development of the exercises, monitoring of the users' performance, and programming of the operations of the robot coach.

\subsubsection{Development of the Exercises}

The developed training program included 8 strength exercises which were part of those recommended by the National Institute on Aging (NIA). ${ }^{6}$ These exercises were chosen because muscle weakness is a widespread problem among

\footnotetext{
5 https://www.ald.softbankrobotics.com/en.

${ }^{6}$ https://www.nia.nih.gov/health/exercise-physical-activity.
}

older adults. This leads to difficulty and inability to perform basic activities such as getting out of bed or from the chair, opening a bottle, and carrying objects. It is also a high risk factor for falls among older adults [48]. Muscle strengthening can help making daily activities easier and hence these exercises are recommended for older adults [49].

The following strength exercises were implemented: bending elbows, raising arms and bending elbows, raising arms and bending elbows 90 degrees, raising arms forward, raising arms horizontally, raising left arm horizontally, raising right arm horizontally, and raising arms horizontally and turning hands. The illustrations for the exercises are presented in Fig. 2.

\subsubsection{Monitoring Users Performance}

Users performance was monitored with the Kinect camera which was programmed to extract the users' skeleton. The skeleton contained the $3 \mathrm{D}$ point position of 25 joints of the user. Each position included a coordinate system $(X, Y, Z)$. $X$ corresponded to the width, $Y$ corresponded to the height and $Z$ to the depth.

$d=\sqrt{\left(x_{2}-x_{1}\right)^{2}+\left(y_{2}-y_{1}\right)^{2}}$

$\cos \beta=\frac{a^{2}+b^{2}-c^{2}}{2 a b}$

The distances and the angles between joints were calculated, as presented in Eqs. (1) and (2) respectively. The following algorithm was developed to check if the user made the correct movement (Algorithm 1). The image of the Kinect's skeletal tracking in real time is also depicted in Fig. 3.

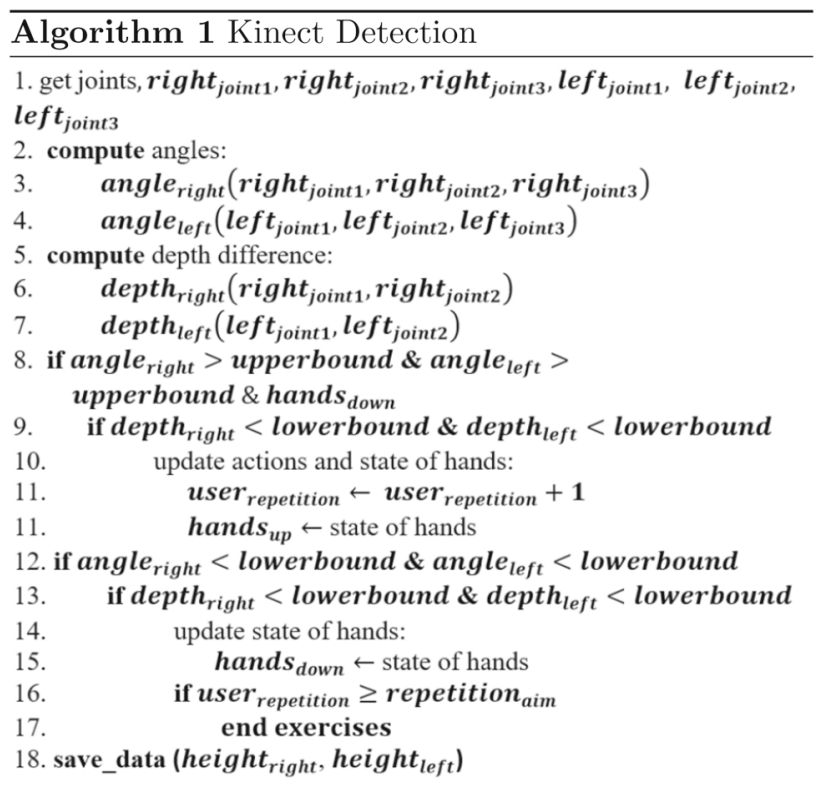


Fig. 2 a bending elbows, $\mathbf{b}$ raising arms and bending elbows, $\mathbf{c}$ raising arms and bending elbows 90 degrees, $\mathbf{d}$ raising arms forward, e raising arms horizontally, $\mathbf{f}$ raising left arm horizontally, $\mathbf{g}$ raising right arm horizontally, $\mathbf{h}$ raising arms horizontally and turning hands

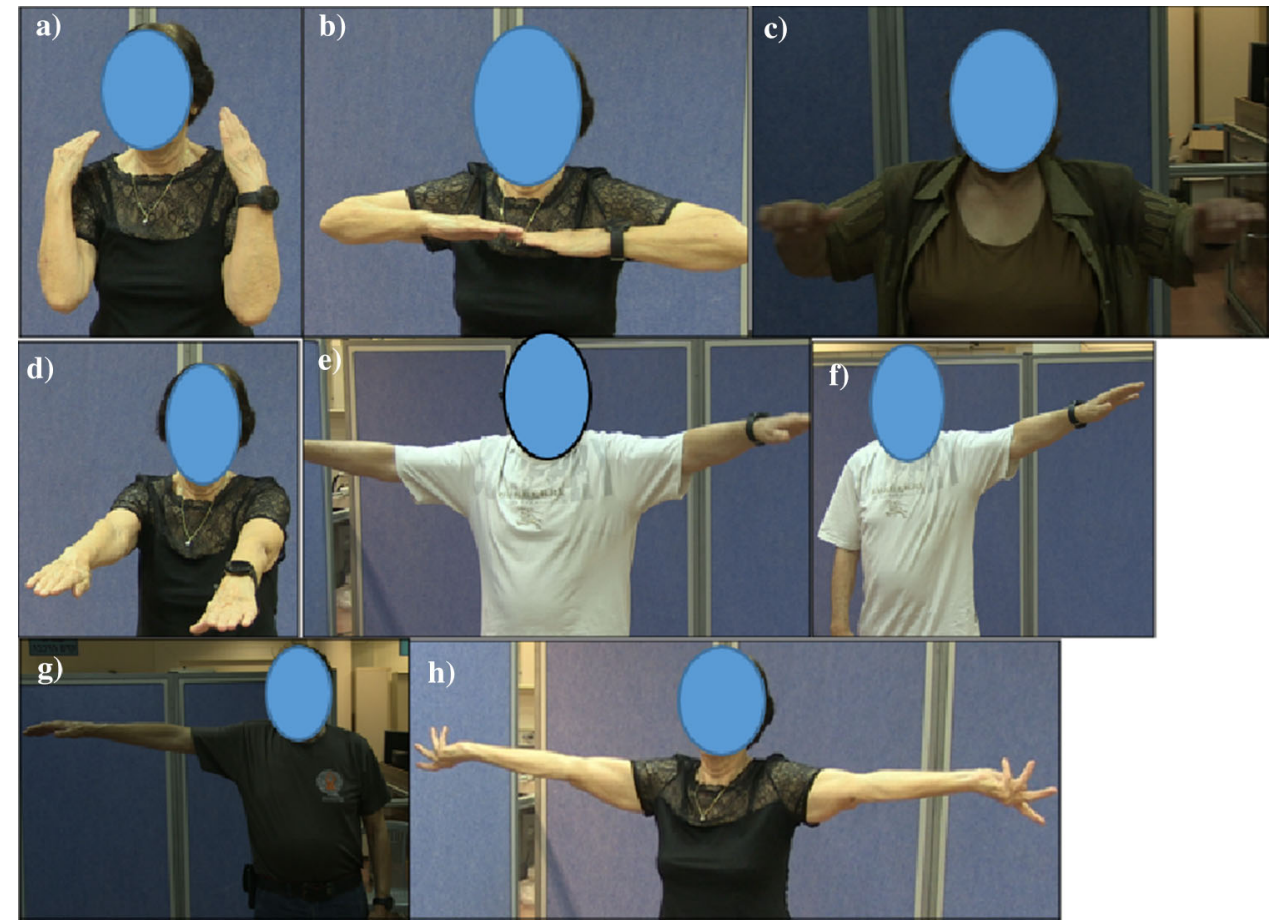

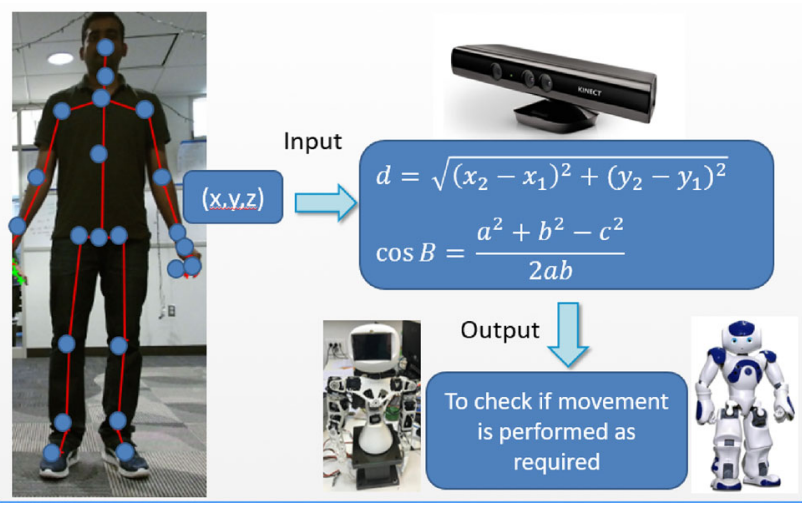

Fig. 3 Kinect's skeletal tracking in real time

\subsubsection{Operations of the Robot Coach}

The two robot coaches (Nao and Poppy) were programmed with the Python programming language. The Nao robot was programmed using the naoqi library while the Poppy robot was programmed with the pypot library. The robots' speech was implemented with existing algorithms in these libraries. This was chosen based on previous research that indicated that human voice is more socially acceptable as compared to synthetic robotic voices [50]. A screen running on raspberry pi was added to the Poppy robot to provide visual (facial) feedback as shown in Fig. 4. It was assumed this would engage the older adults more as noted in previous research regarding feedback and humanoid facial design $[25,35,36,51]$.

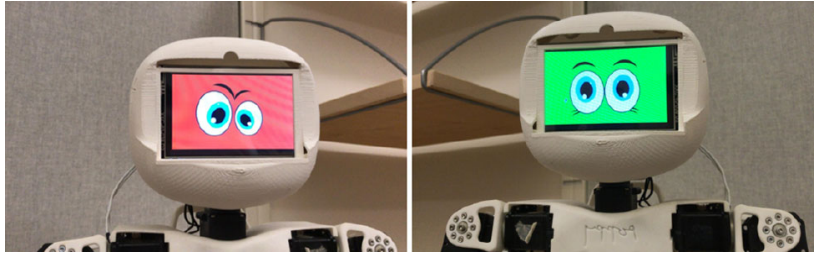

Fig. 4 Visual feedback of Poppy Robot

The session began with the robot standing in front of the user. The robot waited until the user stood in front of it (Fig. 5). It introduced itself as the users' exercise coach. It asked the user to raise his right hand if he/she wanted to start the training. Then, the robot started the session with instructions on what exercise should be done and also demonstrated how it should be done. At the end of the session, the robot thanked the user for his/her participation and said goodbye (Fig. 6). The process for the exercises is given in Fig. 7 and can be seen in the video: https://smartrobabcbgu.wixsite.com/ iemirl/interactive-robotics-research-netwo.

\section{Method}

\subsection{Model}

The model for the study was designed based on the "Technology Acceptance Model" [52]. The independent variables in the experiment were the mode and timing of feedback and type of robot. Although both Poppy and Nao are humanoid 


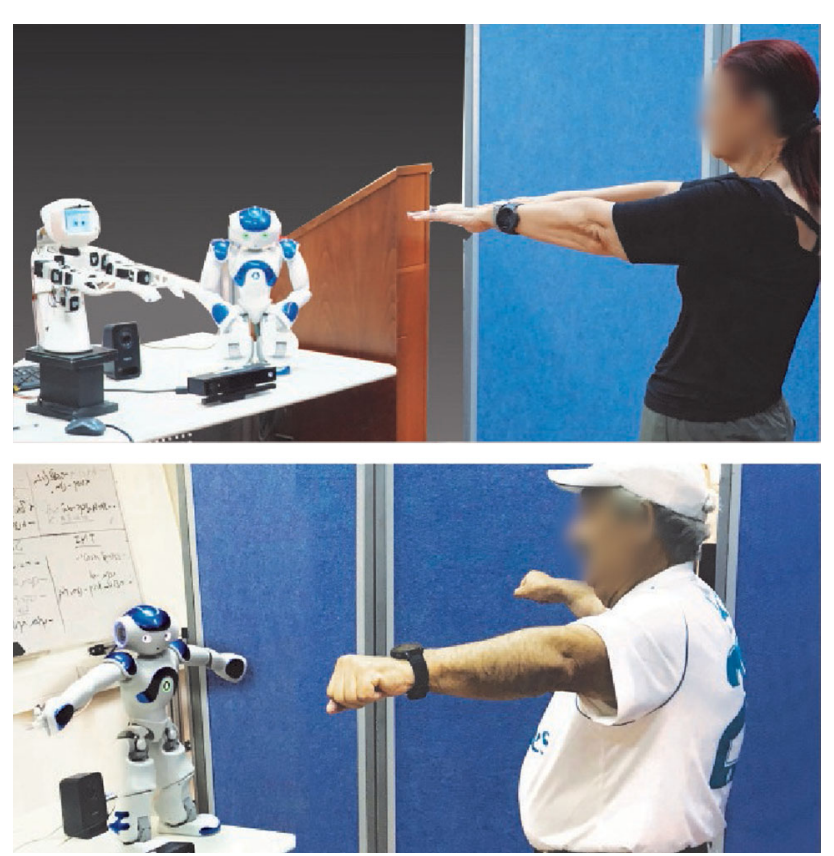

Fig. 5 Robot demonstrating exercise for participants

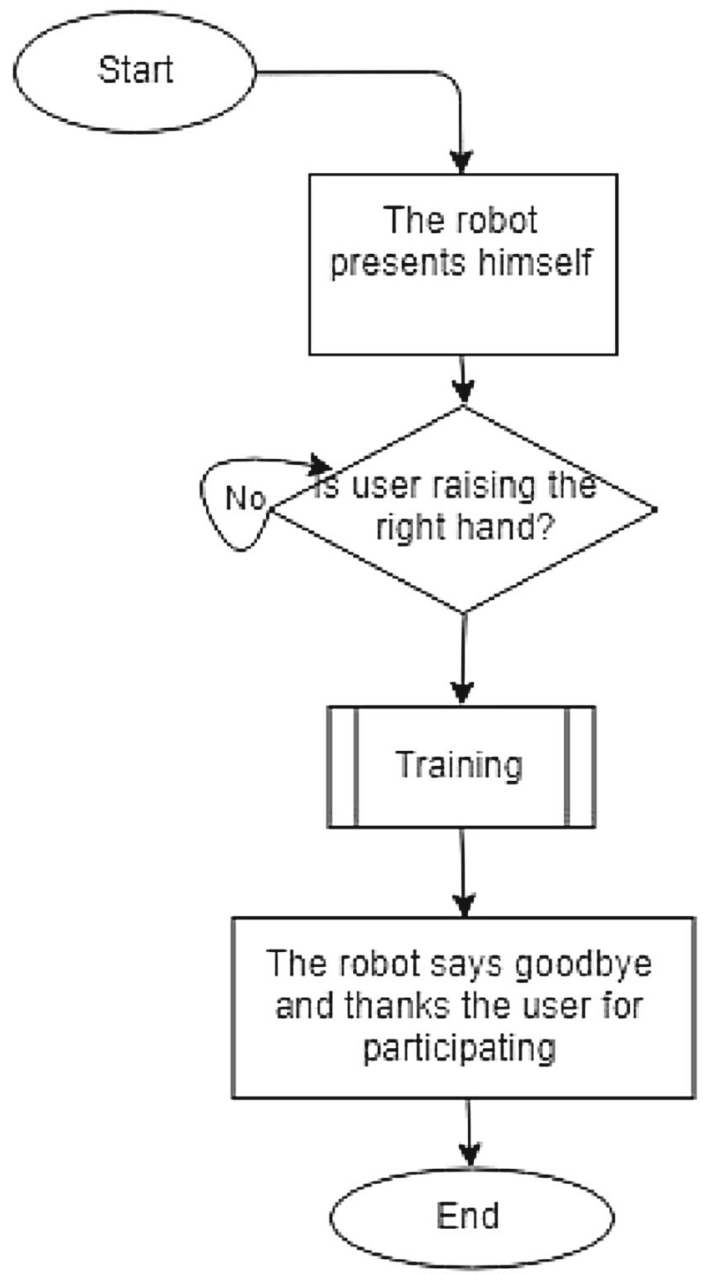

Fig. 6 Main Function robots, Poppy was hypothesized to be more likable due to the facial impression that was added using the LCD screen and due to its appearance which is less toy-like. This conforms with the study of the design and perception of humanoid robot headed by DiSalvo et al. [51] where they emphasized the significance of well expressed robot eyes in the human's perception of the robot. Additionally, Poppy's movements reach a wider range than the Nao and therefore its demonstration of exercises might look to the users more real. The dependent variables were the perceived usefulness, ease of use, attitude and behavioral intention to use the system as depicted in Fig. 8 . These were measured objectively and subjectively. The following hypotheses were proposed:

- H1 - Hla: Older adults will perceive the system as more useful in conditions with audio and visual feedback compared to conditions when only audio feedback is present. $H 1 b$ : Older adults will perceive the system as more useful with continuous feedback compared to discrete feedback.

- H2 - Older adults will perceive the system as more useful while interacting with Poppy robot compared to the Nao robot.

- H3 - H3a: Older adults will perceive the system as easier to use when receiving audio and visual feedback compared to only audio feedback. $H 3 b$ : Older adults will perceive the system as easier to use with continuous feedback compared to discrete feedback.

- H4 - Older adults will perceive the system as easier to use when interacting with Poppy robot (mechanical like) compared to Nao robot (toy-like).

- H5 - Older adults will have a better positive attitude while training with Poppy robot than with Nao robot.

- H6 - H6a: Older adults will have a more positive attitude while using the system with audio and visual feedback than with only audio feedback. H6b Older adults will have a more positive attitude while using the system with continuous feedback than with discrete feedback.

- H7 - The behavioral intention to use the system of the older adults will be higher with Poppy robot than with Nao robot.

- H8 - H8a: The behavioral intention to use the system of the older adults will be higher with audio and visual feedback than with only audio feedback. H8b The behavioral intention to use the system of the older adults will be higher with continuous feedback than with discrete feedback.

- H9 - Higher perceived usefulness of the system will influence a positive attitude to use the system.

- H10 - Higher ease of use of the system will influence a positive attitude to use the system.

- H11 - Positive attitude will influence higher behavioral intention to use the system. 
Fig. 7 Strength Exercises

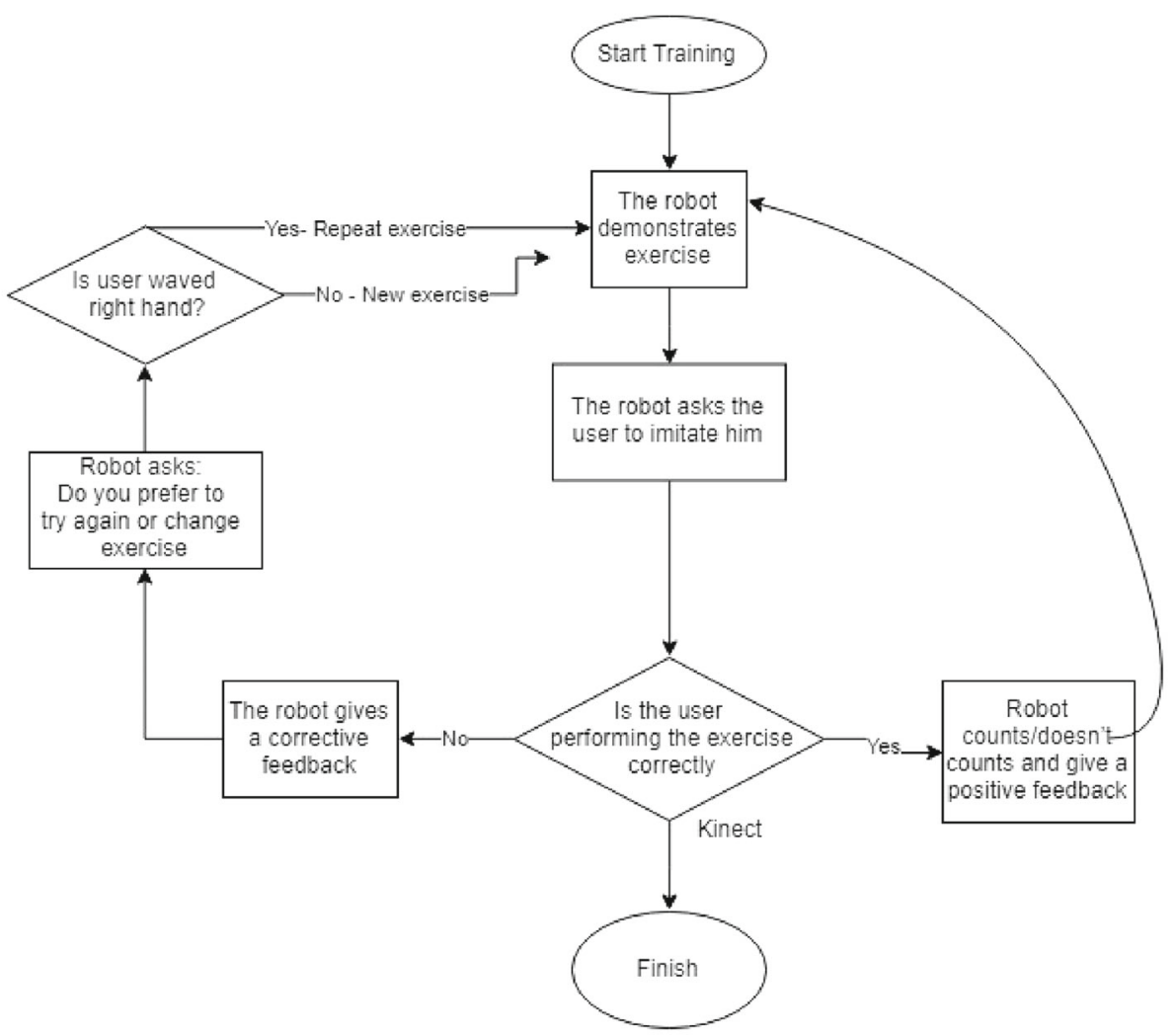

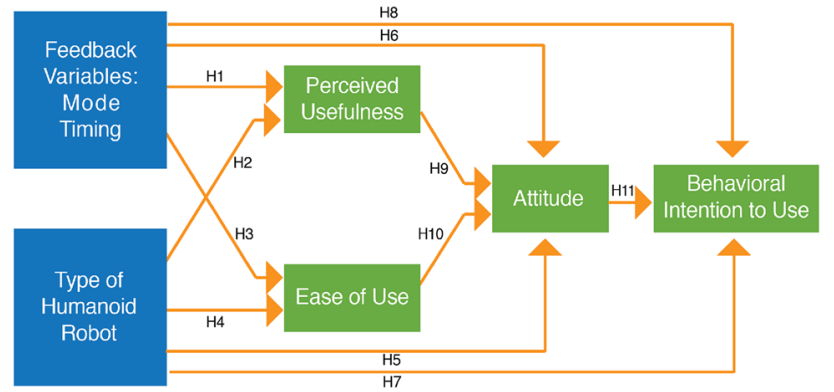

Fig. 8 The study model (based on the Technology Acceptance Model [52])

\subsection{Experimental Design}

A between and within participants experimental design was conducted with three independent variables (Table 1): mode of feedback (audio and a combination of audio and visual), timing of feedback (discrete and continuous) and type of robot (Poppy-mechanical looking and Nao-toy like). The participants were distributed in 4 groups. Each participant experienced one combination of mode and timing of feedback (between-subjects) with both of the humanoids robots, Poppy and Nao, (within-subjects).

Audio feedback was provided as a recorded nonsynthesized female voice. This was identical for both robots. For the discrete mode of feedback, a spoken message approv-
Table 1 Experimental design

\begin{tabular}{lll}
\hline Mode / Timing & Discrete & Continuous \\
\hline Audio & Poppy & Nao \\
& Nao & Poppy \\
Audio and visual & Nao & Poppy \\
& Poppy & Nao \\
\hline
\end{tabular}

ing or disapproving the users performance at the end of each exercise was used. For the continuous mode, a counting of the repetition of movements during the exercises was used, in addition to the discrete feedback provided. Visual feedback was implemented only for the discrete mode and was provided differently for each robot according to its capabilities. For the Nao robot, visual feedback was provided using its LED lights (green or red) on its eyes and body. For the Poppy robot visual feedback was provided by presenting a positive green face or a negative red one on the LCD screen (as can be shown in Fig. 4). The order of presentation of robots (Nao-Poppy, Poppy-Nao) was randomized to account for potential bias.

\subsection{Experimental Procedure}

The experiment included two sessions where participants interacted with a different robot in each session. In each ses- 
sion the user was engaged with the robot to carry out the exercises demonstrated by the robot. The user was prompted by the robot to imitate it. There was an introduction session by the robot as described in Fig. 6. Then, the robot proceeded to the actual strength exercises. The exercises were monitored by the Kinect camera to ensure compliance with the robots' instructions.

\subsection{Participants}

Thirty two healthy older adults were recruited by snowball sampling which started through advertisements at the following sources: Ben-Gurion University's Center of Digital Innovation healthy aging innovation $\mathrm{lab},{ }^{7}$ an older adults local club in Beer Sheva, a local police pensioners club, BGU's older adults working force and older adults who participated in former experiments that took place in our labs.

The participants were composed of 18 females and 14 males aged between 70 and $88(M=77.4, S D=5.8)$. The educational level of $6.3 \%$ of the participants was Ph.D., $15.6 \%$ had a masters degree, $28.1 \%$ had a bachelors degree, $31.3 \%$ had a secondary education and $18.8 \%$ had other education. All recruited participants contacted the authors and filled the consent form independently.

\subsection{Evaluation}

The dependent variables were assessed objectively and subjectively.

\subsubsection{Objective Performance Measures}

A compilation of the objective measures taken during the study are presented in Table 2 .

Comfort of the participants was considered while assessing the ease of use of the system. Comfort was measured through the heart rate (HR) readings of the participants during the physical exercises $[53,54]$. It also reflected, to some extent, the physical demand placed on the participants [55]. These measurements were acquired from a Garmin watch worn by the participants along the experiments (Forerunner 235 series). ${ }^{8}$ Heart rate change (HR change) was calculated based on the heart rate readings before and after the exercise session as presented in Eq. (3).

$H R$ Change $=\frac{H R \text { after }-H R \text { before }}{H R \text { before }}$

\footnotetext{
7 https://www.cdi-negev.com/project/the-healthy-aging-simulationcenter/.

${ }^{8}$ https://buy.garmin.com/en-US/US/p/529988.
}

Table 2 Objective measures

\begin{tabular}{lll}
\hline Dependent variable & Measurement \\
\hline Ease of use & Comfort & heart rate change [53,54] \\
& Understanding & Reaction time (s) [56] \\
& & Participant continued with \\
& the exercise after the robot \\
& & had stopped \\
& & Eye contact (duration \\
Attitude & Engagement & of gazes at the robot) \\
& & [57] \\
& & Success rate \\
\hline
\end{tabular}

The following measures were acquired from the video recordings of the sessions. Understanding was measured in terms of the time (seconds) it took participants to react to the robot's instructions. This could be an indication of how much understanding the participant had regarding the instruction the robot gave. Another objective measure of understanding taken were observations of participants who continued with the exercise after the robot had stopped. In some instances, the robot completed the exercise before the participants. Understanding the robots' instructions and feedback implies that the participant continues and completes the number of repetitions instructed by the robot even after the robot has completed its own rounds. We used this as a measure of assessing how well the participants comprehended the instructions and feedback given by the robot.

The attitudes of the participants in terms of engagement and adherence to training were objectively assessed as eyecontact duration and success rate (SR) respectively. The eye-contact duration was determined by watching the videos of the trials after the experiments and calculating the ratio of the participants" "no eye-contact time" to trials total time. The success rate of the participants in the exercises was computed based on the number of exercises completed in the total number of exercises as shown in Equation (4).

$S R=\frac{\text { exercises completed }}{\text { sum of exercises }}$

\subsubsection{Subjective Performance Measures}

The subjective measures were collected through questionnaires which involved questions about the participants' experience with the robot, technology acceptance and negative attitude towards robots. The pre-trial questionnaire used was composed of demographics questions for the participants, the Negative Attitudes Towards Robots Scale (NARS) [58], and Technology Assessment Propensity (TAP) [59]. NARS questionnaire examines the participants perception of 
Table 3 Post trial questionnaire

\begin{tabular}{|c|c|c|}
\hline \multicolumn{2}{|c|}{ Dependent variable } & Question \\
\hline \multicolumn{2}{|c|}{ Perceived usefulness } & $\begin{array}{l}\text { I would be willing to train with } \\
\text { the robot again because it had } \\
\text { value to me }\end{array}$ \\
\hline \multirow[t]{3}{*}{ Ease of use } & Comfort & $\begin{array}{l}\text { I felt nervous during the activity } \\
\text { felt comfortable during the } \\
\text { interaction }\end{array}$ \\
\hline & Understanding & $\begin{array}{l}\text { I understood the robot well } \\
\text { during the interaction }\end{array}$ \\
\hline & Effort & $\begin{array}{l}\text { I put a lot of effort into this } \\
\text { activity }\end{array}$ \\
\hline \multirow[t]{4}{*}{ Attitude } & Engagement & $\begin{array}{l}\text { I concentrated on the activity } \\
\text { for the entire session }\end{array}$ \\
\hline & Trust & $\begin{array}{l}\text { I felt like I could really trust } \\
\text { this robot }\end{array}$ \\
\hline & Satisfaction & $\begin{array}{l}\text { I was satisfied by the robot's } \\
\text { performance during this } \\
\text { activity }\end{array}$ \\
\hline & Enjoyment & I enjoyed the activity \\
\hline Intention to Use & Acceptance & $\begin{array}{l}\text { I would like to exercise with } \\
\text { the robot in the future }\end{array}$ \\
\hline
\end{tabular}

Table 4 Final Questionnaire

1. Should the robot count?

2. Which robot did you understand better?

3. Which system would you choose to use?

4. Would you like to train with the system in the future?

technology and robots while TAPs questionnaire examines the participants level of technological knowledge. The participants responded to the questionnaires on a 5-point Likert scale ranging from " 1 = strongly disagree" to " 5 = strongly agree". The post trial questionnaire and the variables it assessed are presented in Table 3. The questionnaire was based on the Almere model [60]. The participants indicated their level of agreement on a 3-point Likert scale ranging from " 1 = disagree" to " 3 = agree". The 3 -point Likert scale was used in the post-trial questionnaire in order to avoid the mental workload some of participants reported in other studies [61] that they experienced while trying to rate their experience on questionnaires of higher scales.

The final questionnaire included questions regarding the evaluation of the robot as exercise coach (Table 4).

\subsubsection{Analyses}

The analysis and the pre-processing of the raw data was conducted with the following statistical programs: SPSS, RStudio, Excel. The influence of the independent variables on the objective dependent variables were evaluated using the generalized linear mixed model (GLMM). The target function was chosen according to the distribution of the independent variable.

\section{Results}

\subsection{Participants Characteristics}

The characteristics of the participants analyzed based on prequestionnaires they filled is described in this subsection. This is analyzed in relation to their responses to the TAP and NARS questionnaires. This was done to observe the overall attitude of the participants to adopting new technology and any predisposition they had towards robot before interacting with the physical training robots. The influence of gender was not compared since there was a significant difference in both age and educational level distributions of the participants which might bias the results.

\subsubsection{TAP_-Technology Adoption Propensity}

The responses of the participants to the TAP questionnaire [59] revealed that $3.23 \%$ of the participants had a low propensity to adopt technology, while $38.71 \%$ and $58.06 \%$ had medium and high propensity adoption levels respectively ( $M$ $=3.54, S D=0.65)$.

$80.65 \%$ of the participants strongly believed that technology provides increased control and flexibility in life. $41.94 \%$ of the participants had a low confidence in their ability to quickly and easily learn to use innovative technologies, as well as a sense of being technological. $32.26 \%$ of the participants had high confidence in such ability, the remaining $25.81 \%$ were indifferent about it. $58.06 \%$ of the participants strongly thought that they were overly dependent on technology, and had a feeling of being enslaved by it, while $35.48 \%$ were neutral about it.

\subsubsection{NARS—Negative Attitude Towards Robots Scale analysis}

The NARS results revealed that $35.48 \%$ of the participants had a negative attitude towards situations and interactions with robots while $51.61 \%$ were neutral about it. $22.58 \%$ had highly negative attitudes towards the social influence of robots, $51.61 \%$ had a low attitude and $25.81 \%$ were neutral about it. $64.52 \%$ had a highly negative attitude towards the concept of robots having emotions, $9.68 \%$ were indifferent about it while $25.81 \%$ had a low negative attitude towards it. 
Fig. 9 Heart Rate Change as influenced by Timing (left) and Mode (right) of Feedback
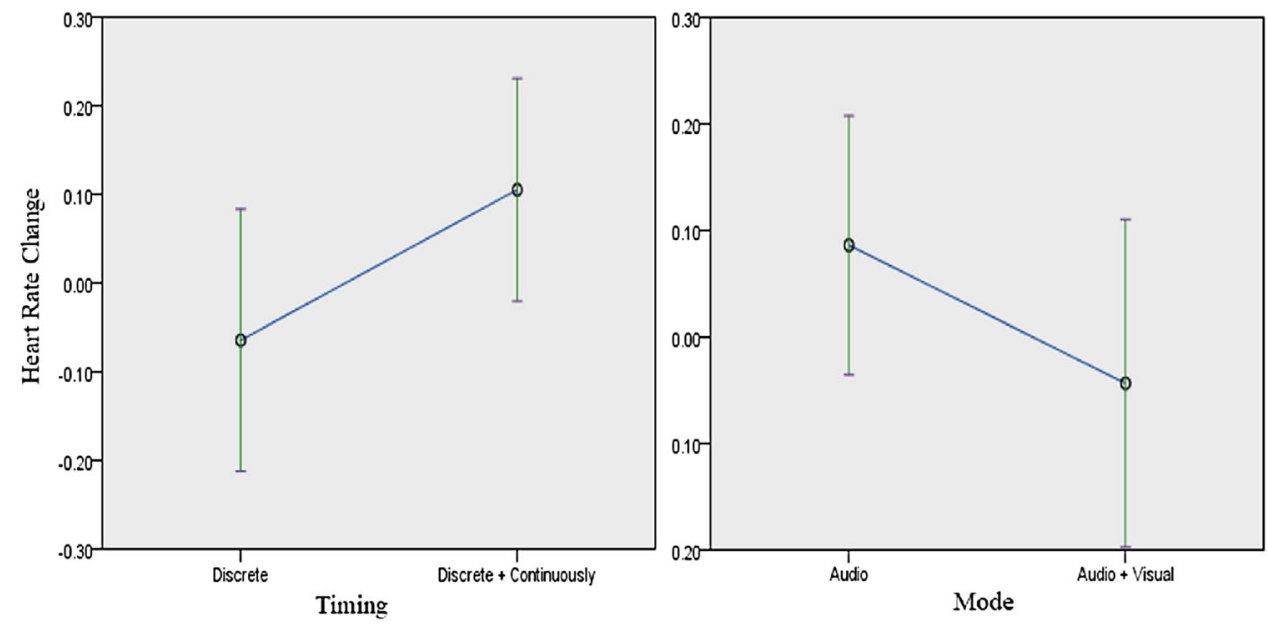

\subsection{Evaluation of the Training}

\subsubsection{Participants' Interaction}

The results of the interaction of the participants with the robot coach for the physical training is described in this subsection. The influence of the main variables tested as the participant interact with the robot are presented in terms of the aforementioned dependent measures.

\subsubsection{Perceived Usefulness}

Majority of the participants indicated through the questionnaire that they perceived the robot as useful for them. More of the participants in the audio feedback group (77.4\%) indicated their willingness to train with the robot in the future compared to participants who experienced both audio and visual feedback $(66.7 \%$ ) (contrary to $H 1 a$ ). More of the participants in the continuous feedback group (77.8\%) indicated their willingness to train with the robot in the future compared to participants who experienced discrete feedback $(64.3 \%)$ (in line with $H 1 b$ ). The robot type did not influence the perceived usefulness - participants rated both robots equally $71.9 \%$ (contradicts $H 2$ ).

\subsubsection{Ease of Use}

The ease of use of the system, as assessed by the change in heart rate, was significantly affected by the mode and timing of the feedback, but not by the robot type. Details of the influence of these independent variables on the heart rate are as follows: in terms of the mode of feedback $(F(1,60)=4.101$, $p=0.047)$, participants with audio feedback $(M=0.23, S D$ $=0.31$ ) had higher change in heart rate than participants with combined audio and visual feedback $(M=0.17, S D=0.23)$ (confirming $\mathrm{H} 3 \mathrm{a}$ ). With regards to the timing of feedback $(F(1,60)=7.674, p=0.007)$, the heart rate change of

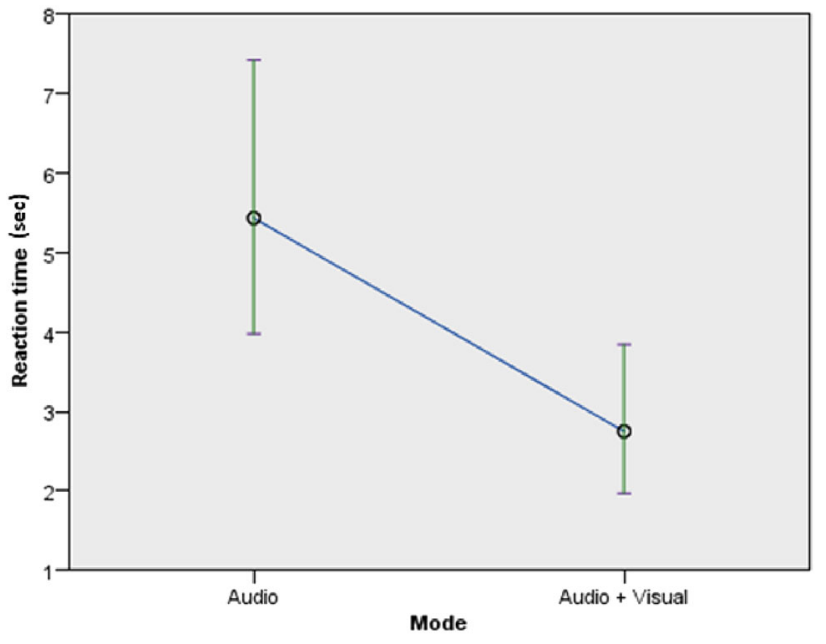

Fig. 10 Reaction time by mode of feedback

participants with continuous feedback $(M=0.26, S D=0.29)$ was higher than that of the participants with discrete feedback ( $M=0.13, S D=0.23$ ) (contradicting $H 3 b)$. This is portrayed in (Fig. 9). Exercising with Nao or Poppy robot did not have a significant difference on the heart rate $(F(1,62)=0.318$, $\rho=0.575$ ) (contrary to $H 4$ ).

The reaction time (in s) of the participants was significantly affected by the mode of feedback but not by the timing of feedback and robot type. Details regarding the influence of the mode of feedback $(F(1,58)=8.931, p=0.004)$ (Fig. 10) revealed that there was a reduction in the reaction time of those using both audio and visual feedback $(M=2.7, S D=$ $1.845)$ as compared to participants with only audio feedback $(M=5.45, S D=7.82)$ (confirming $H 3 a)$.

In terms of the timing of feedback $(F(1,58)=0.704, p=$ $0.405)$, there was a reduction in the reaction time for participants who experienced continuous feedback $(M=3.53, S D$ $=5.165)$ as compared to participants with discrete feedback $(M=4.54, S D=6.21)$ (in line with $H 3 b)$. With regards to 


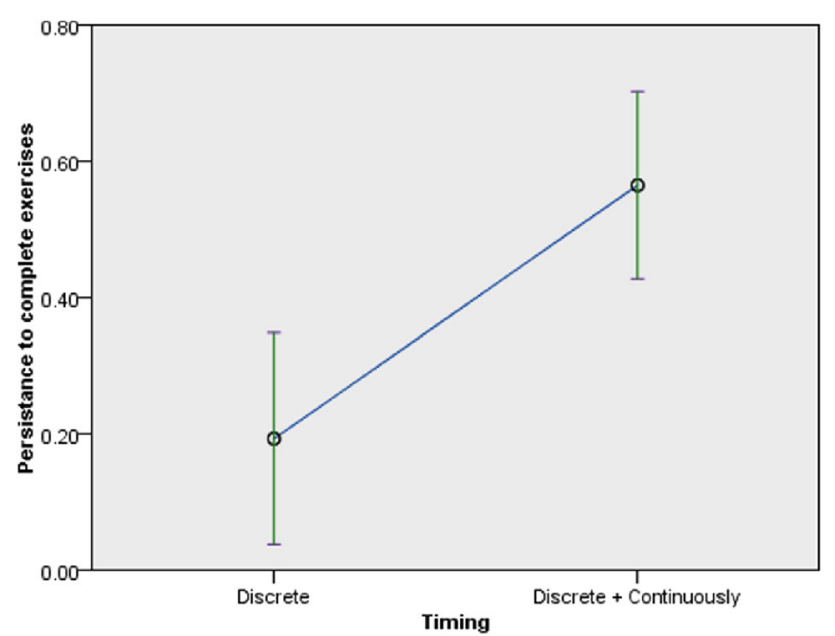

Fig. 11 Persistence to complete exercise by timing of feedback

the robot type $(F(1,60)=0.011, \rho=0.918)$, the reaction time of participants that used the Poppy robot $(M=3.9, S D$ $=6.05$ ) was shorter than participants who used the Nao robot $(M=4.06, S D=5.23)$ (in line with $H 4)$.

Regarding the persistence to complete exercises, timing of feedback had significant influence but the mode of feedback and robot type did not have significant influences. Details of the influences on the persistence to complete exercises revealed the following: in terms of the timing of feedback $(F(1,60)=12.822, p=0.001)$ (Fig. 11), the participants persistence to complete the exercises with continuous feedback $(M=0.57, S D=0.45)$ was higher than the persistence with discrete feedback $(M=0.18, S D=0.37$ ) (confirming $H 3 b)$. In terms of the mode of feedback $(F(1,60)=2.697$, $p=0.106)$, audio and visual feedback $(M=0.5, S D=0.47)$ influenced higher persistence than audio feedback $(M=0.3$, $S D=0.41$ ) (in line with $H 3 a$ ). In terms of the robot type $(F(1,62)=0.677, p=0.414)$, the persistence of participants with the Poppy robot $(M=0.35, S D=0.45)$ was lower than that of participants who used the Nao robot $(M=0.45$, $S D=0.46$ ) (contrary to $H 4)$.

Almost all the participants indicated in the questionnaire that they understood the robot well during the interaction. Regarding the feedback mode, higher percentage in the audio feedback group (96.8\%) indicated that they understood the system better compared to participants who experienced the combined audio and visual feedback $(87.9 \%)$ (contrary to $\mathrm{H} 3 \mathrm{a}$ ). Regarding the feedback timing, all the participants in the continuous feedback group indicated that they were comfortable with the system while $82.1 \%$ of the participants who experienced discrete feedback indicated that they were comfortable (in line with $H 3 b$ ). There was only a slight difference in the robot type preference regarding the comfort- $90.6 \%$ preferred Poppy while $93.8 \%$ preferred Nao (contrary to $H 4$ ).

Most participants noted that the activity did not require much effort from them. The participants in the audio and visual feedback group (78.8\%) reported that the training required less effort compared to participants who experienced only the audio feedback $(67.7 \%)$ (in line with $\mathrm{H} 3 a$ ). Regarding the timing of feedback, the participants in the continuous feedback group $(80.6 \%)$ reported that they exerted less effort compared to participants who experienced discrete feedback $(64.3 \%)$ (in line with $H 3 b)$. There was only a slight difference in the robot type preference regarding the effort, $75 \%$ preferred Poppy while $71.9 \%$ preferred Nao (in line with $H 4$ ). The participants had the opportunity to select both robots if they liked both robots or none if they liked neither of them. These percentages, therfore, do not add up to $100 \%$ because some of the participants selected both robots.

\subsubsection{Attitude}

Engagement, as measured by the ratio of the participants' "no eye-contact time" to trials total time, was significantly affected by the mode and timing of feedback, as well as the robot type. Considering the details of the eye-contact time ratio with respect to mode of feedback, participants who experienced visual and audio feedback were more engaged than participants who experienced audio feedback $(F(1,60)=4.622, p=0.036)$ (Fig. 12 right). The ratio of participants who experienced audio and visual feedback $(M=0.036, S D=0.06)$ was lower than participants with audio feedback $(M=0.403, S D=0.0763)$ (confirming H6a). With respect to timing of feedback $(F(1,60)=23.157, p$ $<0.001$ ) (Fig. 12 left), participants who experienced continuous feedback were more engaged than participants who experienced discrete feedback. The ratio for participants with continuous feedback $(M=0.03, S D=0.048)$ was lower compared to participants with discrete feedback $(M=0.0483$, $S D=0.865)$ (confirming $H 6 b)$. With respect to robot type $(F(1,61)=35.257, p<0.001)$ (Fig. 13), participants who interacted with Poppy robot were more engaged than participants who interacted with Nao robot. The ratio of the participants" "no eye-contact time" to trials total time, with the Poppy robot $(M=0.029, S D=0.0492)$ was lower than participants who used the Nao robot $(M=0.463, S D=0.08)$ (confirming H5).

Regarding the subjective assessment of engagement through the questionnaires, the majority of the users indicated that they were engaged in the activity throughout the session. In terms of the feedback mode, all the participants in the audio and visual feedback group indicated they were engaged with the system while $93.5 \%$ of the participants who experienced audio feedback reported that they were engaged with the system (in line with $\mathrm{H} 6 \mathrm{a}$ ). The timing of the feedback and the robot type did not influence the engagement. The engagement was significantly affected by the users' perceived ease of use (comfort $F(1,57)=17.603, p<0.001$, understanding $F(1,57)=153.335, p<0.001)$ )(confirming 
Fig. 12 No eye contact by timing and mode of feedback
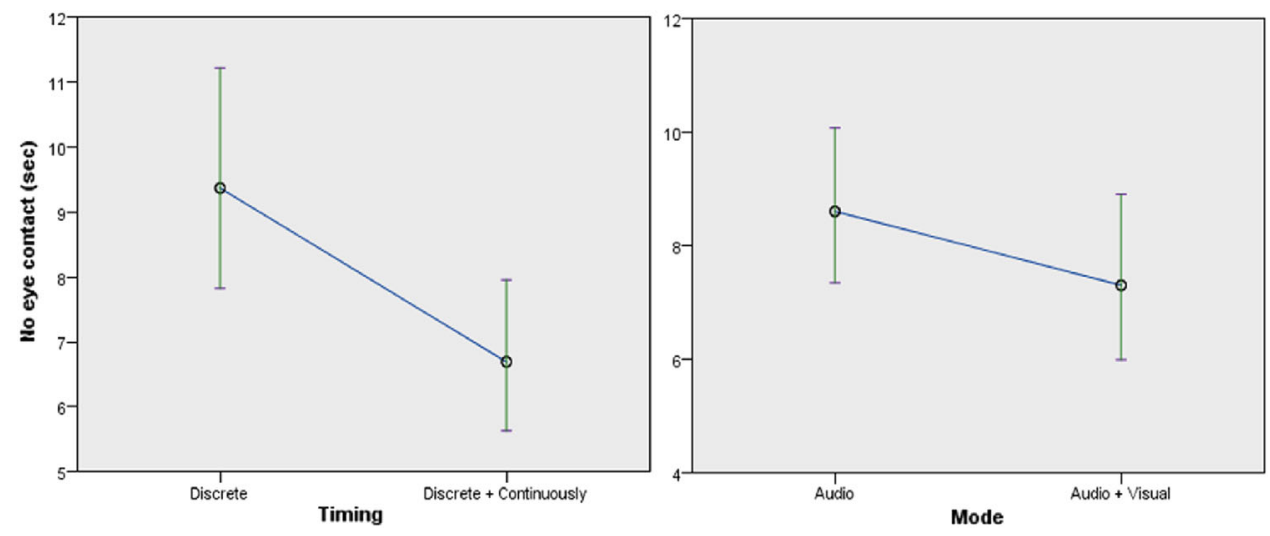

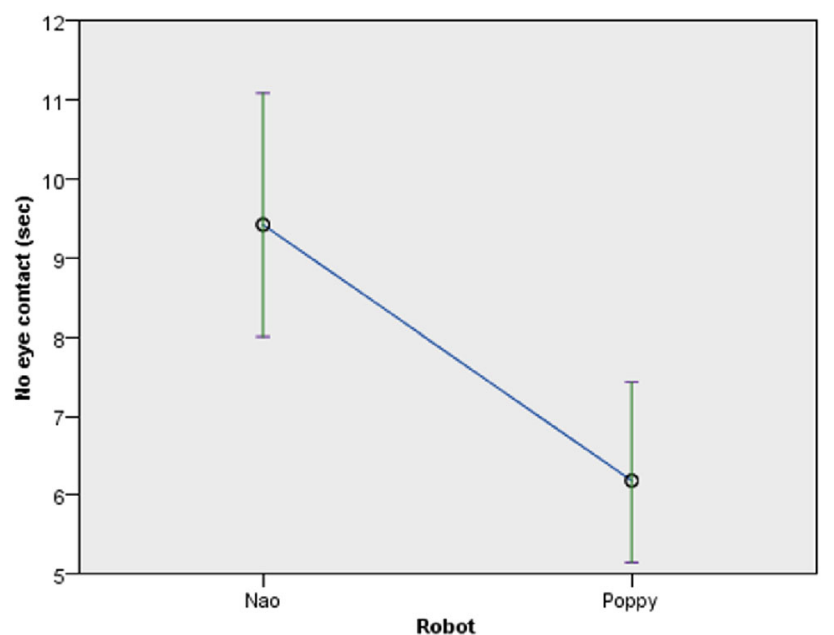

Fig. 13 No eye contact by robot type

H10). Engagement was also significantly affected by the perceived usefulness $(F(2,60)=7.069, p=0.002)($ confirming H9).

Most of the participants indicated in the questionnaire that they trusted the robot. With respect to the feedback timing, most participants in the continuous feedback group (88.9\%) indicated their trust compared to participants who experienced discrete feedback (71.4\%) (in line with $H 6 b$ ) . With respect to the robot type, more participants who trained with Poppy $(84.4 \%)$ trusted the robot than participants who trained with Nao (78.1\%) (in line with H5). There was only a slight difference in the feedback mode preference regarding trust $78.8 \%$ preferred the audio and visual while $83.9 \%$ preferred audio (contrary to H6a). Based on the subjective assessment, the trust was significantly affected by the understanding of the system $(F(1,56)=9.67, p=0.003)($ confirming H1O) and by the perceived usefulness $(F(2,60)=4.725, p=0.012)$ (confirming H9).

Majority of the participants also indicated in the questionnaire that they were satisfied by the robots' performance (with remaining 6/64 unsatisfied and 5/64 neutral). With respect to the feedback mode, more of the participants in the audio feedback group (90.3\%) reported higher satisfaction from the robot compared to participants who experienced audio and visual feedback ( $81.8 \%$ ) (contrary to $H 6 a$ ). With respect to the feedback timing, more of the participants in the continuous feedback group (94.4\%) reported higher satisfaction compared to participants who experienced the discrete feedback (75\%) (in line with $H 6 b$ ). The satisfaction of users who interacted with the Poppy robot $(90.6 \%)$ was higher than the users who interacted with the Nao robot $(81.3 \%$ ) (in line with $H 5$ ). Based on the subjective assessment, the satisfaction of the users was significantly affected by the users perceived usefulness $(F(2,60)=4.911, p=0.011)$ (confirming $H 9)$.

Regarding enjoyment, most of the participants also indicated in the questionnaire that they enjoyed the activity. In terms of the timing of the feedback, more of the participants in the continuous feedback group (94.4\%) indicated their enjoyment compared to participants who experienced discrete feedback (75\%) (in line with $H 6 b$ ). In terms of robot type, there was only a slight difference in the participants' reported enjoyment while interacting with the robots- $84.4 \%$ preferred Poppy while $78.1 \%$ preferred $\mathrm{Nao}$ (in line with $\mathrm{H} 5$ ). In terms of the feedback modes, audio and visual feedback was preferred $(81.8 \%)$ over only audio feedback (80.6\%) (in line with $H 6 a$ ). The enjoyment from the system was also significantly affected by the users perceived usefulness $(F(2,60)=$ $8.106, p=0.001$ ) (confirming H9). The results revealed that $97.8 \%$ of the participants would be willing to train with the robot in the future because it added value to them and they enjoyed the activity.

The success rate of the participants was significantly affected by the timing of feedback, marginally affected by the robot type but not affected by the mode of feedback. The overall success rate was $73 \%$ (taking all the trials into consideration). With respect to the timing of feedback $(F(1,377)=$ $4.485, p=0.035$ ) (Fig. 14), the success rate of participants with continuous feedback was $80 \%$ while that of participants with discrete feedback was $63.9 \%$ (confirming $H 6 b$ ). With respect to the robot type $(F(1,379)=3.694, p=0.055)$, $76.6 \%$ of the participants succeeded better with the Poppy 


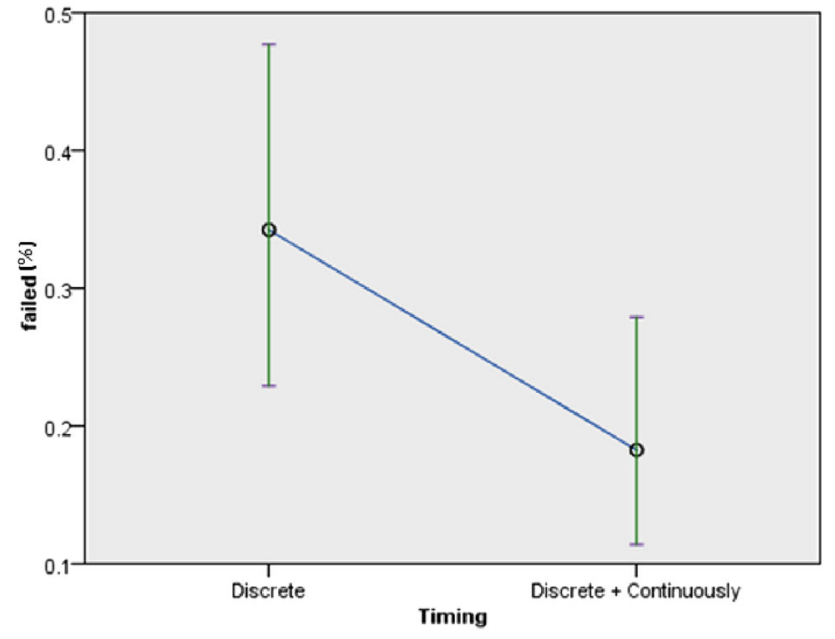

Fig. 14 Success rate based on timing of feedback

robot as compared to the session with the Nao robot (which resulted in $69 \%$ success rate) (confirming $H 5$ ). With respect to the feedback mode $(F(1,377)=2.032, p=0.155)$, participants who experienced audio and visual feedback had a success rate of $78.8 \%$ while the success rate decreased to $67 \%$ for participants who experienced only audio feedback (in line with $H 6 a$ ).

\subsection{Intention to Use}

Most of the participants indicated in the questionnaires their intention to use the system. With respect to the mode of feedback, more participants in the audio feedback group $(80.6 \%)$ expressed their intention to use the system compared to participants in the audio and visual feedback group (72.7\%) (contrary to $\mathrm{H} 8 \mathrm{a}$ ). With respect to the timing of feedback, a higher percentage of the participants in the continuous feedback group $(80.6 \%)$ expressed their intention to use the system compared to participants in the discrete feedback group (71.4\%) (in line with $\mathrm{H} 8 \mathrm{~b}$ ). With respect to the robot type, a higher percentage of participants who trained with Poppy robot (81.3\%), expressed their intention to use the system compared to participants who trained with Nao robot (71.9\%) (in line with $H 7$ ). The behavioral intention to use the robot was significantly affected by the users' enjoyment $(F(2,53)=7.421, p=0.001)$. Analysis of results revealed that $92.3 \%$ of the participants who enjoyed the activity would like to exercise with the robot in the future (confirming H11).

\section{Discussion}

\subsection{Overall Assessment of the Participants and Interaction}

The TAP and NARS results provided some general background about the participants' willingness to explore new technology. This is depicted in the results where more than $95 \%$ of the participants had at least a medium propensity to adopt new technology. Also, the fact that about half of the participants had a neutral attitude towards robots provided a fair basis for comparison of the main variables in the participants' interaction with the robot.

In terms of the main variables assessed, the timing of feedback and the robot type influenced most of the interaction variables (confirming $H 3 b, H 5, H 6 b$, and in line with $H 1 b$, $H 4, H 7, H 8 b)$. The mode of feedback influenced only some of the interaction parameters (confirming $\mathrm{H} 3 \mathrm{a}$ and $\mathrm{H} 6 \mathrm{a}$ ). A depiction of the overall assessment for selected variables under ease of use, attitude, intention to use is presented in Fig. 15. The effect of each of these variables on the interaction is discussed below in detail.

\subsection{Mode of Feedback}

Combining visual and audio feedback, especially in the system that included the Poppy robot, helped the users to understand the instructions of the robot better [62]. It reduced their reaction time and increased the persistence of training. We believe that visual feedback combined with audio will

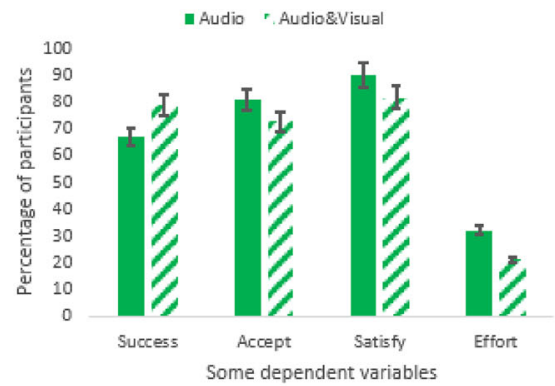

(a)

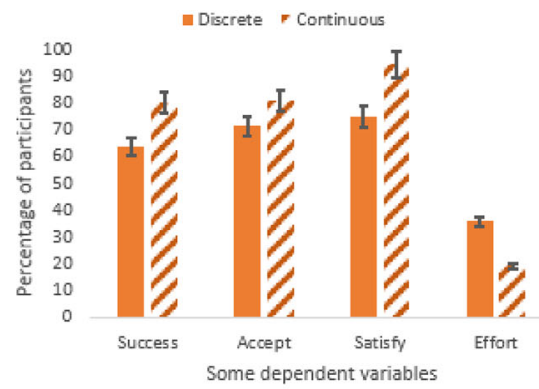

(b)

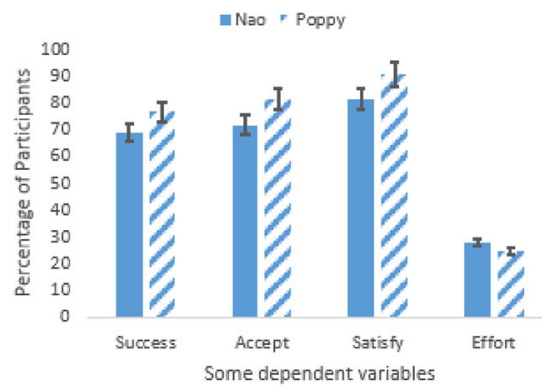

(c)

Fig. 15 Overall participants' assessment regarding influence of: a feedback mode, $\mathbf{b}$ feedback timing, $\mathbf{c}$ robot type. Success = Success rate, Accept = Acceptance, Satisfy = Satisfaction 
help the older adults to understand the system even if they have hearing limitations and as a result do not hear the audio feedback.

The positive effect the combined audio and visual feedback had on the ease of use and positive engagement by the system aligned with the findings of another study [37] that stated that verbal feedback supported by another feedback modality provides more positive outcome.

Existing studies recommend that feedback should be adequate and informative [63]. To avoid overloading the user with information, the information content should be minimal [64]. In our study the information provided was just related to the number of times the user should perform the exercises. At the end of the exercise, the robot commended the user whenever the user succeeded and also asked if the user liked to do some more exercises.

Based on the assessment of the ease of use, attitude and intention to use, we recommend the audio and visual as the mode of feedback which provided higher success rate.

\subsection{Timing of Feedback}

The continuous feedback seemed to have positively influenced the success rate, engagement and the enjoyment of the system. Trust of the participants also seemed to build with the continuous feedback because it seemed to keep the users better informed during the exercise session and not only at the end.

Continuous feedback with counting helped part of the users keep track of the number of right steps and repetitions they had made. Some of the participants with discrete feedback experienced uncertainties regarding their performances in the exercise; they were unsure if they made the correct movement and they were not confident about it. This correlates with the existing literature which states that continuous feedback keeps the users constantly aware of the state of the interaction at every point in time [39]. However, some noted that they preferred the system without counting feedback. We assume that for those people, the robot's feedback in 'counting' form during the exercise, could have been excessive, as observed in some studies that too much information could cause confusion for the users [64]. However, the results in the current study are in line with the literature [40] where continuous feedback was found to provide better understanding, enjoyment, and trust of the system by the users. Continuous feedback was also observed to improve the flow of interaction.

\subsection{Robot Type}

The Poppy robot engaged the users more than the Nao robot. We think that the facial expression on the screen of Poppy had some influence on the positive perception of the users as noted in previous literature [35]. Such facial expressions seem to make the robots behavior better understandable and more attractive corresponding to previous research [25]. Another reason might be the more mechanical look of the Poppy versus the humanoid toy look of the Nao robot.

The users also seemed to trust the Poppy robot more than the Nao robot. A reason could be due to the observable mechanical parts and wires on the Poppy robot which may have given it more of the semblance of a robot compared to the Nao robot.

\subsection{Limitations}

Some of the limitations of this research were related to:

- Variability in the participants-there is high variability in the personality differences of older adults, and this influences their preferences.

- Novelty effect-it was the first time that the users interacted with a robotic coach and their assessments may change over an extended period of interaction.

- More assessments with the gaze monitoring systemthis could be taken to improve the accuracy of the gaze duration but was not taken in this study in order to avoid burdening the participants.

- Cognitive, hearing and vision condition of the participants-a standard assessment of these measures were not taken. It is noteworthy that cognitive, hearing or visual impairments can affect the interaction of the users with the robot and influence the results and therefore should be considered in future studies.

\section{Conclusions and Future Work}

The robotic system was designed to motivate older adults to engage more in physical exercises. Continuous feedback provided in combined audio and visual mode, using a mechanical-like robot increased ease of use for the older adults. These resulted in a better positive attitude and intention to use. However, the combined audio and visual feedback and robot type did not influence the perception of the older adults regarding the usefulness of the robot and their intention to use.

Participants used the system without problems, and understood the interaction with the robot despite the fact that most of them were novice users. The eagerness of the participants to train with a robotic coach revealed a potential of the system to be used as a personal physical trainer for the older adults.

Future work should include additional exercises for the robotic system. Aerobics and lower body exercises could also be included as complementary exercises for more holistic 
physical training sessions for the older adults. Adding difficulty levels for the users that will be adaptive to the users' performance and level is also recommended for further study.

Incorporating an emotion recognition learning algorithm in the system has the potential to improve the system feedback. Such a learning algorithm can enable the system to classify the users emotion (bored, exhausted, fascinated, happy, etc.) and thus provide better feedback with recommendations for improved performance (more challenging exercises, extended training, games, etc.).

Incorporating an imitation learning algorithm to mirror the movements of the users can provide real-time assessment of the users' performance. It could help the users see the kind of movements being made and guide them in correcting wrong movements. It could also enable the inclusion of additional tailored design exercises provided by physical therapists or personal trainers.

Ongoing research is aimed at performing a long-term study with more participants (with different older adults age groups and gender) that will assess a wider change of preferences and explore the differences in the reaction and preferences of the older adults over a longer period. Additionally, we are developing a more holistic training system by adding cognitive training and relaxation exercises which have proven necessary along the COVID-19 pandemic in which many older adults were quarantined at home for extended periods.

On the whole, the robotic system developed and evaluated in this study reveals the potential of improving the physical training experience of older adults with a robotic coach and the importance of including best-fit feedback to improve its usability and acceptance.

Funding This research was partially supported by the EU funded Innovative Training Network (ITN) in the Marie Skodowska-Curie People Programme (Horizon2020):

SOCRATES (Social Cognitive Robotics in a European Society training research network), Grant agreement number 721619 and by Ben-Gurion University of the Negev through the Helmsley Charitable Trust, the Agricultural, Biological and Cognitive Robotics Initiative, the Marcus Endowment Fund, and the Rabbi W. Gunther Plaut Chair in Manufacturing Engineering.

\section{Compliance with ethical standards}

Conflict of interest The authors declare that they have no conflict of interest.

Open Access This article is licensed under a Creative Commons Attribution 4.0 International License, which permits use, sharing, adaptation, distribution and reproduction in any medium or format, as long as you give appropriate credit to the original author(s) and the source, provide a link to the Creative Commons licence, and indicate if changes were made. The images or other third party material in this article are included in the article's Creative Commons licence, unless indicated otherwise in a credit line to the material. If material is not included in the article's Creative Commons licence and your intended use is not permitted by statutory regulation or exceeds the permitted use, you will need to obtain permission directly from the copyright holder. To view a copy of this licence, visit http://creativecomm ons.org/licenses/by/4.0/.

\section{References}

1. Nations U (2017) World population prospects: key findings and advance tables. the 2017 revision

2. McMURDO ME, Rennie L (1993) A controlled trial of exercise by residents of old people's homes. Age Ageing 22(1):11-15

3. Salguero A, Martínez-García R, Molinero O, Márquez S (2011) Physical activity, quality of life and symptoms of depression in community-dwelling and institutionalized older adults. Arch Gerontol Geriatr 53(2):152-157

4. Phillips EM, Schneider JC, Mercer GR (2004) Motivating elders to initiate and maintain exercise. Arch Phys Med Rehabil 85:52-57

5. Brox E, Konstantinidis ST, Evertsen G, Fernandez-Luque L, Remartinez A,Oesch P, Civit A (2016) Gameup: Exergames for mobility - a project to keep elderly active. In: XIV Mediterranean conference on medical and biological engineering and computing. Springer, New York, pp 1225-1230

6. Franco JR, Jacobs K, Inzerillo C, Kluzik J (2012) The effect of the nintendo wii fit and exercise in improving balance and quality of life in community dwelling elders. Technol Health Care 20(2):95115

7. Toulotte C, Toursel C, Olivier N (2012) Wii fit $®$ training vs. adapted physical activities: which one is the most appropriate to improve the balance of independent senior subjects? a randomized controlled study. Clin Rehabil 26(9):827-835

8. Crespo AB, Idrovo GG, Rodrigues N, Pereira A (2016) A virtual reality uav simulation with body area networks to promote the elders life quality. In: 2016 1st International conference on technology and innovation in sports, health and wellbeing (TISHW). IEEE, pp 1-7

9. Paul L, Brewster S, Wyke S, McFadyen AK, Sattar N, Gill JM, Dybus A, Gray CM (2017) Increasing physical activity in older adults using starfish, an interactive smartphone application (app); a pilot study. J Rehabil Assist Technol Eng 4:2055668317696236

10. Guneysu A, Arnrich B (2017) Socially assistive child-robot interaction in physical exercise coaching. In: 26th IEEE international symposium on robot and human interactive communication (ROMAN). IEEE, pp 670-675

11. Ramgoolam D, Russell E, Williams AB (2014) Towards a social and mobile humanoid exercise coach. In: 2014 9th ACM/IEEE international conference on human-robot interaction (HRI). IEEE, pp 274-275

12. Fasola J, Matarić MJ (2013) A socially assistive robot exercise coach for the elderly. J Human-Robot Interact 2(2):3-32

13. Vasco V, Willemse C, Chevalier P, De Tommaso D, Gower V, Gramatica F, Tikhanoff V, Pattacini U, Metta G, Wykowska A (2019) Train with me: a study comparing a socially assistive robot and a virtual agent for a rehabilitation task. In: International conference on social robotics. Springer, New York, pp 453-463

14. Omri A-S (2019) Robotic system for physical training of older adults. Master's thesis, Ben-Gurion University of the Negev

15. Zafrani O, Nimrod G (2018) Towards a holistic approach to studying human-robot interaction in later life. Gerontologist 59(1):e26e36

16. Wiederhold BK (2017) Robotic technology remains a necessary part of healthcare's future editorial 
17. Bemelmans R, Gelderblom GJ, Jonker P, De Witte L (2012) Socially assistive robots in elderly care: a systematic review into effects and effectiveness. J Am Med Dir Assoc 13(2):114-120

18. McColl D, Louie W-YG, Nejat G (2013) Brian 2.1: a socially assistive robot for the elderly and cognitively impaired. IEEE Roboti Autom Mage 20(1):74-83

19. Sabelli AM, Kanda T, Hagita N (2011) A conversational robot in an elderly care center: an ethnographic study. In: 2011 6th ACM/IEEE international conference on human-robot interaction (HRI). IEEE, pp 37-44

20. Khosla R, Chu M-T (2013) Embodying care in matilda: an affective communication robot for emotional wellbeing of older people in australian residential care facilities. ACM Trans Manag Inf Syst (TMIS) 4(4): 18

21. Broadbent $E$ (2017) Interactions with robots: the truths we reveal about ourselves. Annu Rev Psychol 68:627-652

22. Jayawardena C, Kuo I, Datta C, Stafford R, Broadbent E, MacDonald B (2012) Design, implementation and field tests of a socially assistive robot for the elderly: Healthbot version 2. In: 4th IEEE RAS \& EMBS international conference on biomedical robotics and biomechatronics (BioRob). IEEE 2012, pp 1837-1842

23. Czaja SJ, Boot WR, Charness N, Rogers WA (2019) Designing for older adults: principles and creative human factors approaches. CRC Press, Boca Raton

24. Garber PR (2008) Performance Feedback. Human Resource Development

25. Mirnig N, Tan YK, Chang TW, Chua YW, Dung TA, Li H, Tscheligi M (2014) Screen feedback in human-robot interaction: how to enhance robot expressiveness. In: The 23rd IEEE international symposium on robot and human interactive communication. IEEE, pp 224-230

26. Lewis L, Metzler T, Cook L (2016) Evaluating human-robot interaction using a robot exercise instructor at a senior living community. In: International conference on intelligent robotics and applications. Springer, New York, pp 15-25

27. Vallerand RJ (1983) The effect of differential amounts of positive verbal feedback on the intrinsic motivation of male hockey players. J Sport Exercise Psychol 5(1):100-107

28. Vallerand RJ, Reid G (1984) On the causal effects of perceived competence on intrinsic motivation: a test of cognitive evaluation theory. J Sport Exercise Psychol 6(1):94-102

29. Ajoudani A, Zanchettin AM, Ivaldi S, Albu-Schäffer A, Kosuge K, Khatib O (2018) Progress and prospects of the human-robot collaboration. Auton Robots 42(5):957-975

30. (2002) C. European Committee for Standardization and C. European Committee for Electrotechnical Standardization. Guidelines for standards developers to address the needs of older persons and persons with disabilities. vol 6, no. 2, pp 1-31

31. Jacko J, Emery VK, Edwards PJ, Ashok M, Barnard L, Kongnakorn T, Moloney KP, Sainfort F (2004) The effects of multimodal feedback on older adults' task performance given varying levels of computer experience. Behave Inform Technol 23(4):247-264

32. Rosati G, Rodà A, Avanzini F, Masiero S (2013) On the role of auditory feedback in robot-assisted movement training after stroke: review of the literature. Comput Intell Neurosci 2013:11

33. Broz P, Ruby T, Belhocine K, Bouley DM, Kayagaki N, Dixit VM, Monack DM (2012) Caspase-11 increases susceptibility to salmonella infection in the absence of caspase-1. Nature 490(7419):288-291

34. Baraka K, Veloso MM (2018) Mobile service robot state revealing through expressive lights: formalism, design, and evaluation. Int $\mathbf{J}$ Soc Robot 10(1):65-92

35. Lang C, Hanheide M, Lohse M, Wersing H, Sagerer G (2009) .Feedback interpretation based on facial expressions in humanrobot interaction. In: RO-MAN the 18th IEEE international sym- posium on robot and human interactive communication. IEEE, pp 189-194

36. Van Breemen A (2004) Bringing robots to life: Applying principles of animation to robots. In: Proceedings of shapping human-robot interaction workshop held at CHI Citeseer, pp 143-144

37. Mirnig N, Riegler S, Weiss A, Tscheligi M (2011) A case study on the effect of feedback on itinerary requests in human-robot interaction. In: RO-MAN. IEEE, pp 343-349

38. Fischer MJ, Kim J, Hansen CJ, Trachewsky JA (2013) .Feedback of channel information in a closed loop beamforming wireless communication system, US Patent 8,345,732

39. Agrawal S, Yanco H (2018) Feedback methods in hri: Studying their effect on real-time trust and operator workload. In: Companion of the 2018 ACM/IEEE international conference on human-robot interaction, Chicago, IL, USA

40. Sanders TL, Wixon T, Schafer KE, Chen JY, Hancock P (2014) The influence of modality and transparency on trust in human-robot interaction. In: IEEE international inter-disciplinary conference on cognitive methods in situation awareness and decision support (CogSIMA), Las Vegas, NV, USA

41. Doisy G, Meyer J, Edan Y (2014) The impact of human-robot interface design on the use of a learning robot system. IEEE Trans Human-Mach Syst 44(6):788-795

42. Złotowski J, Proudfoot D, Yogeeswaran K, Bartneck C (2015) Anthropomorphism: opportunities and challenges in human-robot interaction. Int J Soc Robot 7(3):347-360

43. Gouaillier D, Hugel V, Blazevic P, Kilner C, Monceaux J, Lafourcade P, Marnier B, Serre J, Maisonnier B (2008) The nao humanoid: a combination of performance and affordability. CoRR abs/0807.3223

44. Lapeyre M, Rouanet P, Grizou J, Nguyen S, Depraetre F, Le Falher A, Oudeyer P-Y (2014) Poppy project: open-source fabrication of $3 \mathrm{~d}$ printed humanoid robot for science, education and art

45. Devanne M (2017) Multi-level motion analysis for physical exercises assessment in kinaesthetic rehabilitation. In: IEEE-RAS 17th international conference on humanoid robotics (humanoids). IEEE, pp 529-534

46. DiFilippo NM, Jouaneh MK (2015) Characterization of different microsoft kinect sensor models. IEEE Sens J 15(8):4554-4564

47. Zhang Z (2012) Microsoft kinect sensor and its effect. IEEE Multim 19(2):4-10

48. Moreland JD, Richardson JA, Goldsmith CH, Clase CM (2004) Muscle weakness and falls in older adults: a systematic review and meta-analysis. J Am Geriatr Soc 52(7):1121-1129

49. Borst SE (2004) Interventions for sarcopenia and muscle weakness in older people. Age Ageing 33(6):548-555

50. Walters ML, Syrdal DS, Koay KL, Dautenhahn K, Te Boekhorst R (2008) Human approach distances to a mechanical-looking robot with different robot voice styles. In: RO-MAN the 17th IEEE international symposium on robot and human interactive communication. IEEE, pp 707-712

51. DiSalvo CF, Gemperle F, Forlizzi J, Kiesler S (2002) .All robots are not created equal: the design and perception of humanoid robot heads. In: Proceedings of the 4th conference on Designing interactive systems: processes, practices, methods, and techniques, pp $321-326$

52. Davis FD (1989) Perceived usefulness, perceived ease of use, and user acceptance of information technology. MIS quarterly, pp 319340

53. Rani P, Sims J, Brackin R, Sarkar N (2002) Online stress detection using psychophysiological signals for implicit human-robot cooperation. Robot 20(6):673-685

54. Rani P, Sarkar N, Smith CA, Kirby LD (2004) Anxiety detecting robotic system-towards implicit human-robot collaboration. Robot 22(1):85-95 
55. Samantha Jo Hensen BSN B, Noe Crespo M, Lopez NV (2017) Measuring physical activity with heart rate monitors/arredondo et al. respond. Am J Public Health 107(12):E24-E25

56. Hellström T, Bensch S (2018) Understandable robots-what, why, and how. Paladyn J Behavl Robot 9(1):110-123

57. Sidner CL, Kidd CD, Lee C, Lesh N (2004) Where to look: a study of human-robot engagement. In: Proceedings of the 9th international conference on Intelligent user interfaces. ACM, pp 78-84

58. Nomura T, Suzuki T, Kanda T, Kato K (2006) Measurement of negative attitudes toward robots. Inter Stud 7(3):437-454

59. Ratchford M, Barnhart M (2012) Development and validation of the technology adoption propensity (tap) index. J Bus Res 65(8):12091215

60. Heerink M, Kröse B, Evers V, Wielinga B (2010) Assessing acceptance of assistive social agent technology by older adults: the almere model. Int J Soc Robot 2(4):361-375

61. Olatunji S, Sarne-Fleischmann V, Honig SS, Oron-Gilad T, Edan Y (2018) Feedback design to improve interaction of person-following robots for older adults
62. Hoecherl J, Schmargendorf M, Wrede B, Schlegl T (2018) Usercentered design of multimodal robot feedback for cobots of humanrobot working cells in industrial production contexts. In: ISR 50th international symposium on robotics, Munich, Germany, pp 1-8

63. Mirnig N, Tscheligi M (2014) Comprehension, coherence and consistency: essentials of robot feedback. In: Robots that talk and listen. Technology and social impact. De Gruyter, pp 149-171

64. Lyons JB (2013) Being transparent about transparency: a model for human-robot interaction. 2013 AAAI Spring Symposium Series. Stanford University, Stanford

Publisher's Note Springer Nature remains neutral with regard to jurisdictional claims in published maps and institutional affiliations. 